Darling argue that if only men could be present at the birth, they too would form strong bonds with their children and take on the care-taking role usually associated with mothers.

In support of this idea, they cite male wild-dogs, male marmosets and other species in which males take an active part in looking after the young. They also quote Rosenblatt's finding that male rats will

IMAGE
UNAVAILABLE
FOR
COPYRIGHT
REASONS

Mother love - black-faced vervet monkey with infant.

begin to lick and retrieve young after they have been exposed to them for several days. The male's tendency to care for young is latent and revealed only if given the opportunity: "And just like a father rat, the human father is denied access to the environmental cues that would turn on his 'maternal' behaviour'" (p.148).

There may or may not turn out to be something in all this. It is an interesting hypothesis, one which is certainly worth thinking about. What is disturbing to me is the way it is put over. Perhaps this is simply because the book is written in a popular style. Maybe words such as "babes" and "critters" have to be used to make sure readers do not feel overwhelmed by technical jargon; maybe a case has to be overstated in order to attract a public who would be bored by too much weighing up of evidence. But do we have to swing from male sexism to an equally unattractive female sexism? If we accept that women may wish and be able to fulfil a wider variety of roles than they often do, do we have to see society purely in terms of womens' choices and womens' destinies?

Shaw and Darling emphasize that "female" does not have to mean passive, meek or monogamous. But at the same time, perhaps unintentionally, they make female wishes and female roles dominant, without explaining why this kind of sexism is any more convincing - or any more acceptable - than the male kind.

Marian Dawkins is Fellow in Biological Sciences at Somerville College, University of Oxford.

\section{Ways to get back to the track}

\section{David Pimentel}

State of the World 1985: A Worldwatch Institute Report on Progress Toward a Sustainable Society.

Project director Lester R. Brown. W.W. Norton: 1985. Pp.301. Hbk $\$ 22.75, £ 18.95 ; p b k \$ 9.50, £ 7.95$.

IN PUBLISHING this detailed analysis of "the state of the world", the Worldwatch Institute has performed a valuable service for the public, government and industry. Examined in it are the interdependence of human population, global environment and world economy. Specifically, the authors assess the effect of population growth on deforestation, overgrazing, soil erosion, atmospheric pollution, and water and energy shortages. With this as a basis, they go on to consider the influence of natural resource degradation and resource shortages on the economy and standard of living of society.

Early in the book Brown and his colleagues tackle the question of whether climate change in some regions of the Earth may be population induced. They suggest that, indirectly, population growth may reduce rainfall because of overgrazing and other activities that remove or reduce vegetation cover. The increased exposure of bare soil increases the albedo: "Where this happens, as on the fringes of the Sahara, the affected areas reflect more heat into space". Canadian meteorologist, Kenneth Hare, who has investigated desertification in Africa, is quoted as concluding that "we seem to have arrived at a critical moment in the history of mankind's relation to climate. For the first time we may be on the threshold of man-induced climatic change". If indeed water shortages are population induced, then the decline can be reversed in some regions only by massive programmes in family planning, tree planting, soil and water conservation, and ecological-agricultural development on a huge scale.

The authors acknowledge the fact that major efforts to produce more food per hectare of land have slowed the growth of hunger, noting that agriculturalists have made use of biological diversity to breed new crop varieties that are more efficient in converting water and fertilizers into grain and other foods. At the same time, farmers have increased the amount of land cultivated and have greatly expanded the use of irrigation and fertilizers. Irrigation, for instance, has grown nearly three-fold since 1950 and fertilizer usage about ninefold during much the same period. All these strategies have increased crop yields.

It remains to be seen, however, how far agricultural technology can go in producing more food from the world's limited arable land resources. We already know that there are certain physical and chemical constraints on the capacity of plants to capture and fix solar energy into biomass. Recognizing such limitations, the authors question whether biotechnology will make the major changes necessary to continue improving yields. A major concern to emerge here is the effect that the rapid loss of biological diversity will have on the success of biotechnology and genetic engineering, but in placing emphasis on this point the authors neglect to explain that most species in nature are vital to the normal functioning of the ecosystem. For example, agriculture cannot function successfully with only its crop and livestock species; many organisms, especially the small organisms (such as microbes and insects) are also essential. Thus on a hectare of good land with ample water, the small organisms outweigh human biomass by at least 200 times and carry out the vital tasks of degrading wastes and chemical pollutants, and of recycling other resources.

In a chapter on energy efficiency, William Chandler reports on the important role that fossil energy plays in producing food, purifying water, protecting us from numerous kinds of diseases and transporting resources from one region to another. Several sound arguments support the view that conservation of energy and improved energy efficiency are necessary for economic improvement in both developing and developed countries. But although fossil energy is essential to our present standard of living, almost everyone agrees that new sources of energy are needed, preferably renewable in form. However, the chapter entitled "Harnessing Renewable Energy" is rather disappointing. Several of the sources cited lack scientific credibility. For example, one paper quoted here reports that producing ethanol from corn grain provides a net energy return. This is not so; in fact, the net energy loss is about 30 per cent greater than the ethanol energy produced.

Also highlighted is the idea of shifting from the corn-soybean crop mix now typical in the mid-west of the United States to a corn-sugar-beet mix. This proposed plan, which is supposed to supply all food needs for livestock plus up to 700 million barrels of ethanol, has numerous technological and agricultural flaws and has been

\section{Conservation in Britain}

In association with the publisher Webb \& Bower, and sponsored by Gulf Oil, the Conservation Foundation have published The Conservation Review, their third annual report for "everyone concerned with preserving our heritage and natural environment".

The Review is intended to increase public awareness of environmental issues and draw attention to the activities of various organizations, local, national and international. Among the contributors are David Bellamy, Patrick Jenkin, Tony Soper and Jean Medawar. Price is hbk £10.95, pbk $£ 4.95$. 
discounted by most energy specialists. Further, nowhere do the authors acknowledge the environmental risks associated with certain renewable systems. For example, the widespread burning of crop residues and dung as a fuel is severely intensifying soil erosion and water run-off, and is robbing the soil of essential nutrients. Because soil erosion and water run-off are a major feature of the Report, it is especially unfortunate that biomass energy systems are not identified as major causes of these problems. There are also drawbacks to hydropower, but again no mention is made of them. Dams and reservoirs have to be constructed to run hydropower systems, and in the United States, for instance, about 13,000 hectares of productive agricultural land has to be flooded per $1 \times 10^{9} \mathrm{kWh} / \mathrm{yr}$ of electricity produced (sufficient electricity for a city of $100,000)$. This is not to imply that hydropower is not a valuable energy system in the United States and many regions of the world, but that environmental risks should be evaluated to determine if the benefits for a region outweigh the costs.

One of the most challenging aspects of the resource and environmental problems facing us today is their "gradual, insidious nature". For example, a single rain storm may erode $1 \mathrm{~mm}$ of soil weighing 15 tonnes from a hectare. That loss may be imperceptible, but it does not take many rain storms and many years to remove the $2.5 \mathrm{~cm}$ of topsoil that generally requires 200 to 700 years to replace. As Brown and Wolf point out, "few countries will succeed in attempts to boost domestic food at the rate demanded by population growth if soildepleting agriculture continues".

The authors of the Report clearly explain that soil, water, energy and biological resources are being threatened not only by the rapidly growing population but also by poor management practices in agriculture and other industries. Further, many excellent plans are suggested for tackling the problems. But, as they caution, longterm solutions will require the efforts of individual intellects and of politicians to get society back to the track - the intellects to identify the direction for change, and political leadership to devise and carry out the appropriate policies for stabilizing populations and effectively managing environmental resources.

State of the World is a thorough and upto-date examination of the influence of mankind on the Earth's various resources. Particularly helpful and timely are the solutions to the complex problems that are identified in the book. This is an exceptionally well-written report which scientists and industrial and political leaders would do well to read and to act upon.

David Pimentel is Professor of Insect Ecology and Agricultural Science at the College of Agriculture and Life Sciences, Cornell University.

\section{Biology as science}

The Cambridge Encyclopedia of Life Sciences.

General editors Adrian Friday and

David S. Ingram.

Cambridge University Press: 1985.

Pp.432. £25, \$45. To be published on 9 May.

TO TRY to encompass within a volume of 432 pages a complete encyclopaedia of the life sciences strikes one as a most noble aim tributors have succeeded in this book to a really remarkable degree.

The volume is divided into three parts: "Processes and Organisation"' (the cell, the organism, genetics, behaviour and sociobiology, ecology); "Environments" (marine, coastal, terrestrial, freshwater and wetland, living organisms as environments); and "Evolution and the Fossil Record" (the evolutionary process, palaeontology, early events in evolution, origin and development of the land flora and fauna, recent history of the flora and fauna). A classification of living organisms, a species index (generic also) and a subject index complete the book.

The contents page refers under Part 2 to what appears to be an unnumbered chapter on biogeographical zones. The relevant pages in fact carry a set of maps only, and neither biogeography nor any names of biogeographical regions appear in the subject index. There are, however, excellent accounts of plate tectonics, numerous maps of the drifting continents, and much information on regional history and animal diversity in the section on the origin and development of the land flora and fauna, the best place to discuss the development of biogeographical diversity.

The book is written in a very readable style and has obviously been most carefully corrected in proof - one of the very few books I have seen in recent years that can be put into the hands of the young without a warning against bad spelling and gram-

\section{A.J. Cain} and a forlorn hope. The editors and con-

mar. It is a model of exposition, excellently illustrated. In the words of the editors:

The Cambridge Encyclopedia of Life Sciences is not a natural history cataloguing the living world, it does not attempt to argue a case for or against biological conservation, nor does it consider the yet greater ethical problems which arise from the genetic manipulation of cells. Instead, the Encyclopedia seeks to present biology as a science, and in addition constitutes a plea for considering all biological phenomena as indissolubly linked, a circumstance which underlies both the frustration and the fascination felt by all life scientists.

Inevitably, the necessary compression means that many topics can only be treated summarily, as a series of key concepts, their interrelations, and a brief mention of their empirical basis. In some ways this is a positive advantage, forcing the writers to get to the real bones of the subject. One could give a series of lectures on the single paragraph (p.296):

Some biologists have argued that if we can reconstruct the pattern of evolution, the phylogeny, this will provide insight into the ways in which evolutionary change occurs. The opposite point of view is that knowledge of the processes of evolutionary change is essential before it is possible to find out the pattern of relationships between organisms.

Yes, indeed!

Equally inevitably, specialists will be dissatisfied because so much can only be mentioned. It would take a team of reviewers as large as the team of authors and editors $(31,22$ of them in Cambridge) to deal with the chapters fully. In my own speciality, I notice only the total absence of ring species and allopolyploid plants from the section entitled "Mechanisms of Speciation", in which too much space is given to the latest fads in speciation theory. As against that, what a pleasure it is to see a proper discussion of parasites in the section on living organisms as environments. Surely there are more species of parasitic than of free-living organisms, yet this major aspect of evolution and the ecosystems of the world is usually mentioned merely in passing except in highly specialized texts.

A.J. Cain is Derby Professor of Zoology at the University of Liverpool.
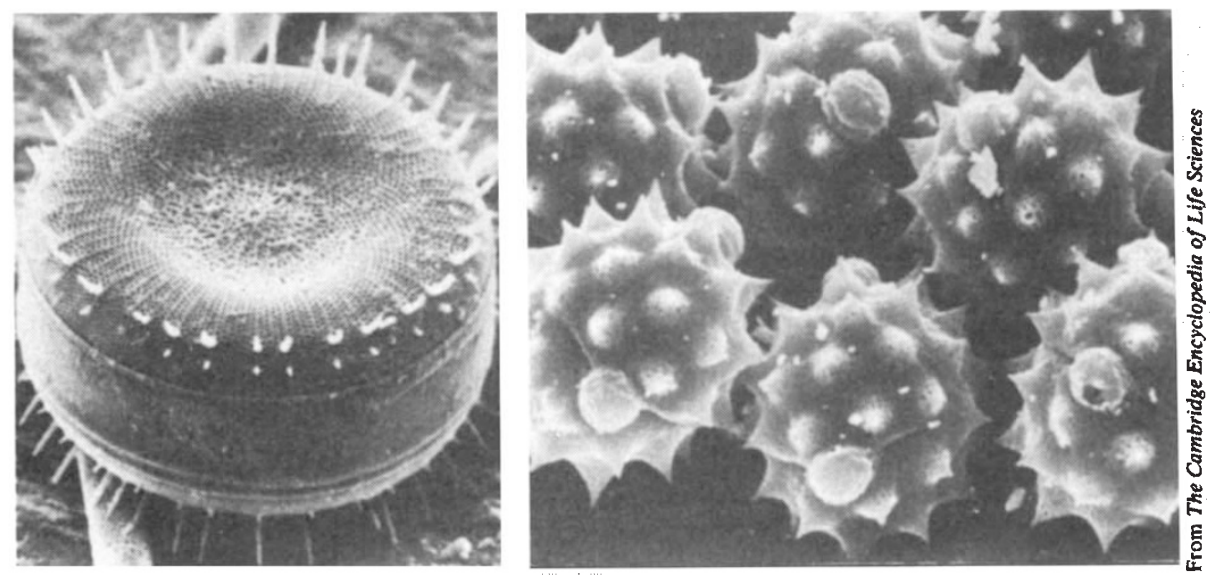

Revelations of the scanning electron microscope - the diatom Stephanodiscus (left) and pollen of Chrysanthemum mycoais. 